\title{
SYNCHROTRON STUDIES OF NARROW BAND MATERIALS
}

\section{Table of Contents}

1. Progress Report.............................................page 2

2. Report figure...............................................page 5

DOE/ER/45416--2

3. Future Plans......................................................page 6

4. Publications and Talks......................................page 7

5. Personnel and support....................................page 8

DE92 016317

\section{Progress Report for $7 / 1 / 91-6 / 30 / 92$}

\section{Activity}

Beamtime Since the time of viting last year's report, we have had three 3-week blocks of beamtime, in April and Nove..ver of 1991 and in February of 1992, on the Ames/Montana beamline at the Wisconsin Synchrotron Radiation Senter (SRC), working with Cliff Olson. These runs continued our program on high temperature superconductors, heavy Fermion and related uranium and rare earth materials, and starte $\downarrow$ some work on transition metal oxides. We have also had beamtime at the Brookhaven NSLS, 5 days of beamtime on the Dragon monochromator, beamline $\mathrm{U} 4 \mathrm{~B}$, studying resonant photoemission of transition metal oxides using photon energies around the transition metal $2 p$ edges. We have another 3 -week block allocated at the SRC for May, 1992 and have applied for comparable amounts of time in the coming year at both SRC and NSLS.

Data analysis and U.M lab studies Data from past runs has been analyzed, and in some cases combined with photoemission and bremsstrahlung isochromat spectroscopy (BIS) distu taken in the home U-M lab (which is supported by a grant from the NSF).

\section{High $\mathrm{T}_{\mathrm{c}}$ and related subjects}

$\mathrm{Bi}_{2} \mathrm{Sr}_{2} \mathrm{BaCu}_{2} \mathrm{O}_{8}$ photoemission lineshape analysis The angle resolved photoemission spectroscopy (ARPES) spectral lineshapes of $\mathrm{Bi}_{2} \mathrm{Sr}_{2} \mathrm{BaCu}_{2} \mathrm{O}_{3}$, very near the Fermi energy $\mathrm{E}_{\mathrm{F}}$ in the normal state, have been taken as evidence for non-Fermi liquid behavior in this material. Following up this idea, we have fit ARPES spectra of $\alpha_{1} i_{2} \mathrm{Sr}_{2} \mathrm{BaCu}_{2} \mathrm{O}_{8}$ taken by Olson et al using normal and marginal Fermi liquid self-energies. Both theories fit the data equally well provided a sufficiently large inelastic background is included. However, the required backgrounds are, respectively, 60 and 15 times larger than that given by usual background subtraction procedures. A paper on this work has been published in the proceedings of a Fermiology Workshop held at Argonne National Laboratory in March, 1991. 
TiTe 2 ARPES In our lineshape fitting effort on $\mathrm{Bi}_{2} \mathrm{Sr}_{2} \mathrm{BaCu}_{2} \mathrm{O}_{8}$ (preceding subtopic) the need to calibrate ARFIS for Fermi liquid materials became obvious. We have selected the quasi two-dimensional material $\mathrm{TiTe}_{2}$ for this purpose and have taken detailed low temperature high resolution ARPES data for a nondegenerate band crossing $E_{F}$. The data are of very high quality. and are shown in Fig 1 of this report. We are now analyzing them using both the Fermi liquid and the marginal Fermi liquid lineshapes to see if the data can distinguish the two theories, and it appears that they definitely favor the Fermi liquid. Preliminary results will be presented at the upcoming March APS meeting.

$\mathrm{Nd}_{2-x} \mathrm{C}_{x} \mathrm{CuO}_{4}$ and $\mathrm{La}_{2-x} \mathrm{Sr}_{\mathrm{x}} \mathrm{CuO}_{4}$ ceramics The two systems $\mathrm{Nd}_{2-x} \mathrm{Ce}_{\mathrm{x}} \mathrm{CuO}_{4}$ and $\mathrm{La}_{2+x} \mathrm{Sr}_{x} \mathrm{CuO}_{4}$ are thought to be electron and hole doped, respectively. In our previous angle integrated photoemission studies on these materials we found that $E_{F}$ for the metals occurs in new states in the gap of the insulator and that $E_{F}$ is in roughly the same position for both systems so that it does not "jump the gap" as one switches from hole to electron doping. Recently X-ray absorption spectroscopy (XAS) studies at the oxygen 1s edge have been interpreted as showing that for hole doping $\mathrm{E}_{\mathrm{F}}$ lies in the insulator valence band and that for electron doping $\mathrm{E}_{\mathrm{F}}$ lies in the insulator conduction band. Since sample variability is well known in these materials, we have repeated our angle integrated studies, including at the same time $O$ is XAS performed by the yield method. We find that the ohotoemission data are the same as previously, and that the XAS data also agree with those of other workers, so the conflict does not have its origin in sample differences. We are currently searching for a unified interpretation of all the data. A report on this work will be made at the upcoming March APS meeting.

$\mathrm{La}_{2-x} \mathrm{Sr}_{x} \mathrm{CuO}_{4}$ ARPES Thus far no ARPES data has been reported for $\mathrm{La}_{2-x} \mathrm{Sr}_{x} \mathrm{CuO}_{4}$. Recently, we obtained single crystals of this material and were very encouraged to find that the crystals give very good X-ray Laue patterns. Unfortunately, to date the ARPES measurements do not reveal sharp features near $E_{F}$.

\section{Heavy-fermion and related materials}

$A_{1-x} U_{x} P_{3}(A=Y, Z r)$ Our studies of $U_{x} Y_{1-x} P_{3}$ are now complete and analyzed. The data consist of synchrotron-excited resonant photoemission for the USf states, combined with U-M lab photoemission data on the valence band and core levels and BIS data for the conduction band 5f states. The clata are correlated with transport measurements performed by our collaborators, the Maple group at U.Cal. San Diego (UCSD) and interpreted as showing that the Fermi energy $E_{F}$ shifts to lower enery with decreasing $x$ as $\mathrm{Y}^{3+}$ replaces $\mathrm{U}^{4+}$. Accompanying this, for $\mathrm{x}<$ 0.3 , the transport properties show the Konjo effect and the BIS spectrum develops a Kondo resonance. Separate PRL's on the transport and spectroscopy have been published, and two Ph.D students, Chris Seaman (UCSD) and Lizhong Liu (U-M) will present invired talks on the work in a symposiurn at the upcoming March APS meeting.

Following up this work, we have also made resonant phoroemission measurements on polycrystalline samples of $\mathrm{Zr}_{1-\mathrm{x}} \mathrm{U}_{\mathrm{x}} \mathrm{Pd}_{3}$. We expect $\mathrm{Zr}$ to have the $4+$ valence state, so that $\mathrm{E}_{\mathrm{F}}$ will not shift, and we will see much different behavior than in $U_{x} Y_{1-x} P d_{3}$. U.M lab photoemission and BIS studies, and UCSD transport studies are also in Frogress. 
$\mathrm{URu}_{2} \mathrm{Si}_{2}$ We have analyzed our low temperature high-resolution ARPES data for single crystals of the heavy-fermion material $\mathrm{URu}_{2} \mathrm{Si}_{2}$. We have compared the results to band theory to the extent possible. Our nomal emission data with varible photon energy $h \nu$, probing the $\Gamma$ to $Z$ direction, show little dispersion. Instead, the spectral peaks occur at energies where the $\Gamma$ to $Z$ band structure implies peaks in the one-dimensional density of states for this direction. In contrast, data taken with fixed photon energy and variable angle away from normal emission show dispersing features. Following other workers, we tentatively understand this to imply a large uncertainty in momentum perpendicular to the surface, due to a small mean free path, and a continued conservation of momentum parallel to the surface. A detailed paper describing this work has been prepared and will soon be submitted to the Physical Review.

Kondo insulators We have begun high resolution studies on a group of small-gap insulating materials which, in the mid-70's were known as mixed valent hybridization gap systems. Recently new materials of this type have been discovered, and it has been realized that the energy gaps are probably related to a small energy scale of the kind involved in the Kondo effect. Thus these materials have a new name-the Kondo insulators, and they now enjoy a revival of theoretical and experimental interest. Thus far we have taken data on $\mathrm{CeFe}_{4} \mathrm{P}_{12}$ and $\mathrm{PrFe}_{4} \mathrm{P}_{12}$. The fomer is thought to be a Kondo insulator and the latter, for contrast, is a metal. These data will be combined with U-M lab data directed at learning the valence of $\mathrm{Ce}$ in this material.

\section{Transition metal oxides}

Resonant photoemission at the transition metal $2 p$ edge At last year's March APS meeting, L.H. Tjeng, a Bell Labs postdoc working on the NSLS Dragon beamline, reported resonant photoemission studies of the $\mathrm{Cu} 3 \mathrm{~d}$ states in $\mathrm{CuO}$ using photons at the $\mathrm{Cu} 2 \mathrm{p}$ edge. He found that the on-off resonance contrast was much larger than for the commonly used resonarice at the $\mathrm{Cu} 3 \mathrm{p}$ edge, offering the possibility to extract the $3 \mathrm{~d}$ emission with the degree of certainty that previously has only been possible in resonant photoemission for rare earth and actinide $4 \mathrm{f}$ and $5 \mathrm{f}$ states. We made an agreement to collaborate with Tjeng and obtained beamtime for such studies for a range of transition metal oxides. Very large samples are needed because of the large beain size for this beamline, and we were able to obtain these from the Purdue Materials Preparation Center. In 5 days of beamtime, high quality data were obtained for $\mathrm{CoO}, \mathrm{MnO}, \mathrm{Fe}_{3} \mathrm{O}_{4}, \mathrm{FeO}$, $\mathrm{V}_{2} \mathrm{O}_{3}$ and $\mathrm{Ti}_{2} \mathrm{O}_{3}$. The initial thrust of the experiments has been to test the systematics of the $3 \mathrm{~d}$ energy level structure of transition metal compounds as postulated in the Zaanen-Sawatzky-Allen classification scheme. Results to date will be reported at the upcoming March APS meeting.

$\mathrm{V}_{2} \mathrm{O}_{3}$ and $\mathrm{Fe}_{3} \mathrm{O}_{4}$ ARPES Two of the materials studied at the NSLS (preceding subtopic), $\mathrm{V}_{2} \mathrm{O}_{3}$ and $\mathrm{Fe}_{3} \mathrm{O}_{4}$ have interesting and famous metal-insulator transitions as a function of temperature. In studies performed at the U-M lab, we observed large spectal differences for the two phases in each material. Since our samples are single crystals of high quality, we have also made high resolution ARPES studies of the phase transition during the SRC experimental period just ended. The data have yet to be analyzed. 


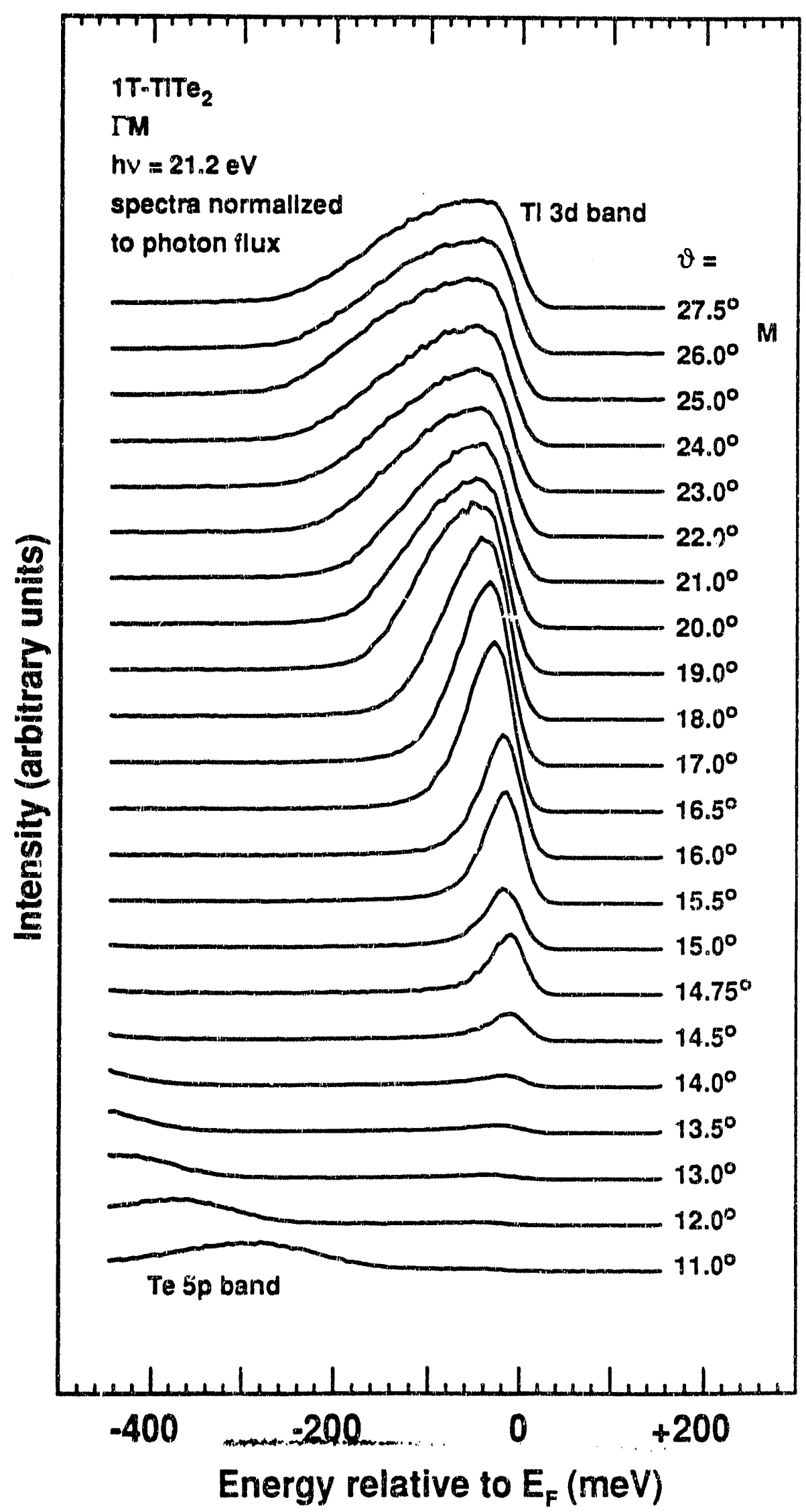

Figure 1 


\section{Future Plans}

\section{High $T_{c}$ and related topics}

1. We will extend the work on $\mathrm{TiTe}_{2}$ to other transition metal dichalcogenides or other paradigm systems.

2. We will continue efforts to obtain high quality ARPES data on $\mathrm{Nd}_{2-x} \mathrm{Ce}_{x} \mathrm{CuO}_{4}$ and $\mathrm{La}_{2-\mathrm{x}} \mathrm{Sr}_{\mathbf{x}} \mathrm{CuO}_{4}$, depending on sample availability.

3. We plan ARPES studies of $\mathrm{TlBa}_{2} \mathrm{Ca}_{2} \mathrm{Cu}_{3} \mathrm{O}_{8}$, single crystals of which we have been promised by Dean Peterson at Los Alamos National Laboratory. The hole concentration of this system can be varied by substituting $\mathrm{Ba}$ and $\mathrm{Pb}$ for $\mathrm{Tl}$, so we may also be able to study the insulator to metal transition in this system.

\section{Heavy-fermion and related materials}

1. We will follow up the work on $Y_{1-x} U_{x} P_{3}$ with studies of $\mathrm{Zr}_{1-x} U_{x} P d_{3}, T_{1-x} U_{x} P_{3}, \operatorname{PrPd}_{3}$, and $\mathrm{Th}_{0.9} \mathrm{U}_{0.1}\left(\mathrm{Pd}_{1-\mathrm{x}} \mathrm{Pt}_{\mathrm{x}}\right)_{3}$.

2. We plan to make further studies of Kondo insulator materials.

\section{Transition metal compounds}

1. We will continue our resonant photoemission studies at the $2 p$ edge of selected transition metal oxides. An aspect not yet pursued involves using the resonance to extract the 3d states of diluted species, such as the $\mathrm{Cr}$ emission in $\left(\mathrm{V}_{1-\mathrm{x}} \mathrm{Cr}_{\mathrm{x}}\right)_{2} \mathrm{O}_{3}$. The $\mathrm{Cr}$ doping considerably changes the insulator to metal transition in $\mathrm{V}_{2} \mathrm{O}_{3}$. We also wish to study other materials such as $\mathrm{Cr}_{2} \mathrm{O}_{3}$ and $\mathrm{CrO}_{2}$ as part of looking at the systernatics of the transition metal oxides.

2. We will continue our ARPES studies of insulator to metal transitions in such systems as $\mathrm{V}_{2} \mathrm{O}_{3}$ and $\mathrm{Fe}_{3} \mathrm{O}_{4}$. We also hope to obtain single crystals of $\mathrm{NiS}$, another material with such a transition.

\section{DISCLAIMER}

\footnotetext{
This report was prepared as an account of work sponsored by an agency of the United States Government. Neither the United States Government nor any agency thereof, nor any of their ernployees, makes any warranty, express or implied, or assumes any legal liability or responsibility for the accuracy, completeness, or usefulness of any information, apparatus, product, or process disclosed, or represents that its use would not infringe privately owned rights. Reference herein to any specific commercial product, process, or service by trade narne, trademark, manufacturer, or otherwise does not necessarily constitute or imply its endorsement, recommendation, or favoring by the United States Government or any agency thereof. The views and opinions of authors expressed herein do not necessarily stute or reflect those of the United States Government or any agency thereof.
} 


\section{4.'Publications and Talks}

\section{Reprints and Preprints}

1. L.Z. Liu, R.O. Anderson and J.W. Allen, "Crucial role of inelastic background subtraction in identifying non-fermi liquid behavior in existing ARPES lineshape data," J. Phys. Chem. Sol. 52, 1473 (1991).

2. C.L. Seaman, M.B. Maple, B.W. Lee, S. Ghamaty, M.T. Torikachvili, J.-S. Kang, L.-Z. Liu, J.W. Allen, and D. L. Cox, "Evidence for the two-channel quadrupolar Kondo effect in $\mathrm{Y}_{1-\mathrm{x}} \mathrm{U}_{\mathrm{x}} \mathrm{Pd}_{3}$," Phys, Rev. Lett. 67, 2882 (1991).

3. L.Z. Liu, J.W. Allen, C.L. Seaman, M.B. Maple, Y. Dalichaouch, J.-S. Kang, M.S. Torikachvili and M.L. Lipez de la torre, "Kondo resonance in $\mathrm{Y}_{1-\mathrm{x}} \mathrm{U}_{\mathrm{x}} \mathrm{Pd}_{3}$," Phys. Rev. Lett. 68, 1034 (1992).

4. J.W. Allen, L.-Z. Liu, R. Claessen, R.O. Anderson, J.-H. Park, J.-S. Kang, C.L. Seaman, M.B. Maple, Y. Dalichaouch, M.L. de la Torre, C.G. Olson, W.P. Ellis, and M.S. Torikachvili, "Electron spectroscopy of strongly correlated electron materials-recent issues and results," to be published in the Proceedings of the Miniworlishop and Adriatico Conference on Strongly Correlated Electron Systems, held July 1991 at ICTP Trieste (World Scientific).

5. L.Z. Liu, J.W. Allen, R.O. Anderson, J.-H. Park, C.G . Olson, S.-J. Oh, J.-S. Kang, W.P. Ellis, Y. Dalichaouch. B.W. Lee and M.B. Maple, "Band dispersion in the heavy-fermion compound $\mathrm{UR}_{2} \mathrm{Si}_{2}$ : An angle-resolved photoemission study," to be submitted to Phys. Rev.

\section{Conference Presentations:}

Invited, Adriatico Research Conference on "Open Problems in Strongly Interacting Electron Systems," July, 1991, ICTP Trieste

J.W. Allen, "Electron spectroscopy of strongly correlated electron materials--recent issues and results."

Invited, 1992 March APS Meeting

L.Z. Liu, "Fermi Level Tuning and the Kondo Resonance in $\mathrm{Y}_{1-\mathrm{x}} \mathrm{U}_{\mathrm{x}} \mathrm{Pd}_{3} . "$

\section{Contributed, 1992 March APS Meeting}

1. R.O. Anderson, R. Claessen, C.G. Olson, R.F. Jardim, J.W. Allen, and M.B. Maple, "Electron spectroscopy study of the M-I transition in p- and n-doped high $T_{c}$ superconductors."

2. J.-H. Park, L.H. Tjeng, R. Claessen, J.W. Allen, and C.T. Chen, "Resonance photoemission of $3 \mathrm{~d}$ transition-metal oxides at the metal $2 \mathrm{p}$ and $\mathrm{O} 1 \mathrm{~s}$ edges."

3. R. Claessen, R.O. Anderson, J.W. Allen, C.G. Olson and W.P. Ellis, "Electron self energies measured by high-resolution angle-resolved photoemission in 1T-TiTe, 


\section{Personnel and Support}

The following personnel are being partially or entirely supported by this contract:

1. U.M graduate student Mr. Robert Anderson. Robert has passed the department qualifying examination, and should achieve Candidacy for the Ph.D by the fall of 1992.

2. U-M graduate student Mr. Jaehoon Park. Mr. Park was an exceptionally good Master's thesis student at the University of Seoul, working with Prof Se-Jung Oh., a former student of mine. He has passed the department qualifying examination, and received the highest score of all the students who took it at the same time. He should achieve Candidacy for the Ph.D by the fall of 1992 .

3. U-M graduate studeent Yuxin Zhang, a second year student, is a new member of the group.

4. Postdoc Dr. Ralph Claessen. Dr. Claessen is partially supported by the Lynen program of the Humboldt Foundation of Germany. This program enables a German postdoc to work with a Humboldt senior awardee, such as the PI, with the awardee providing roughly half the total cost during the first two years.

5. Prof. Bryan Coles, of the Imperial College in London. Prof. Coles, an internationally recognized expert on narrow band materials, visited several groups at U-M in the period Oct-Dec. 1991.

\section{Other support:}

Our NSF grant, which supports the U-M laboratory activity, was renewed last year, beginning in July 1991. This grant had supported Lizhong Liu, who obtained his Ph.D. and left in September 1991 for a postdoc position at Yale. Although Lizhong was officially supported by the NSF grant, he was primarily responsible for some of the synchrotron work described in this report. The NSF grant now provides partial support for Anderson and Park.

Outside collaborations:

We have leveraged our support by having Dr. W. Ellis, from the Los Alamos National Laboratnry, Dr. J.-S. Kang of the Research Institute for Science and Technology in Korea, and Prof. S.-J. Oh, of the Seoul National University, and Dr. Cliff Olson of the Ames Laboratory, collaborating in the experiments. Each is funded by their own institutions. Samples for the experiments are provided mostly by the Prof. Brian Maple's group at UCSD in an active collaboration which combines transport and spectroscopy studies. We also obtain samples from other sources.

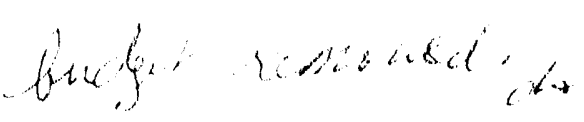

\section{DISCLAIMER}

This report was prepared as an account of work sponsored by an agency of the United States Government. Neither the United States Government nor any agency thereof, nor any of their employees, makes any warranty, express or implied, or assumes any legal liability or responsibility for the accuracy, completeness, or usefulness of any information, apparatus, product, or process disclosed, or represents that its use would not infringe privately owned rights. Reference herein to any specific commercial product, process, or service by trade name, trademark, manufacturer, or otherwise does not necessarily constitute or imply its endorsement, recommendation, or favoring by the United States Government or any agency thereof. The views and opinions of authors expressed herein do not necessarily state or reflect those of the United States Government or any agency thereof. 

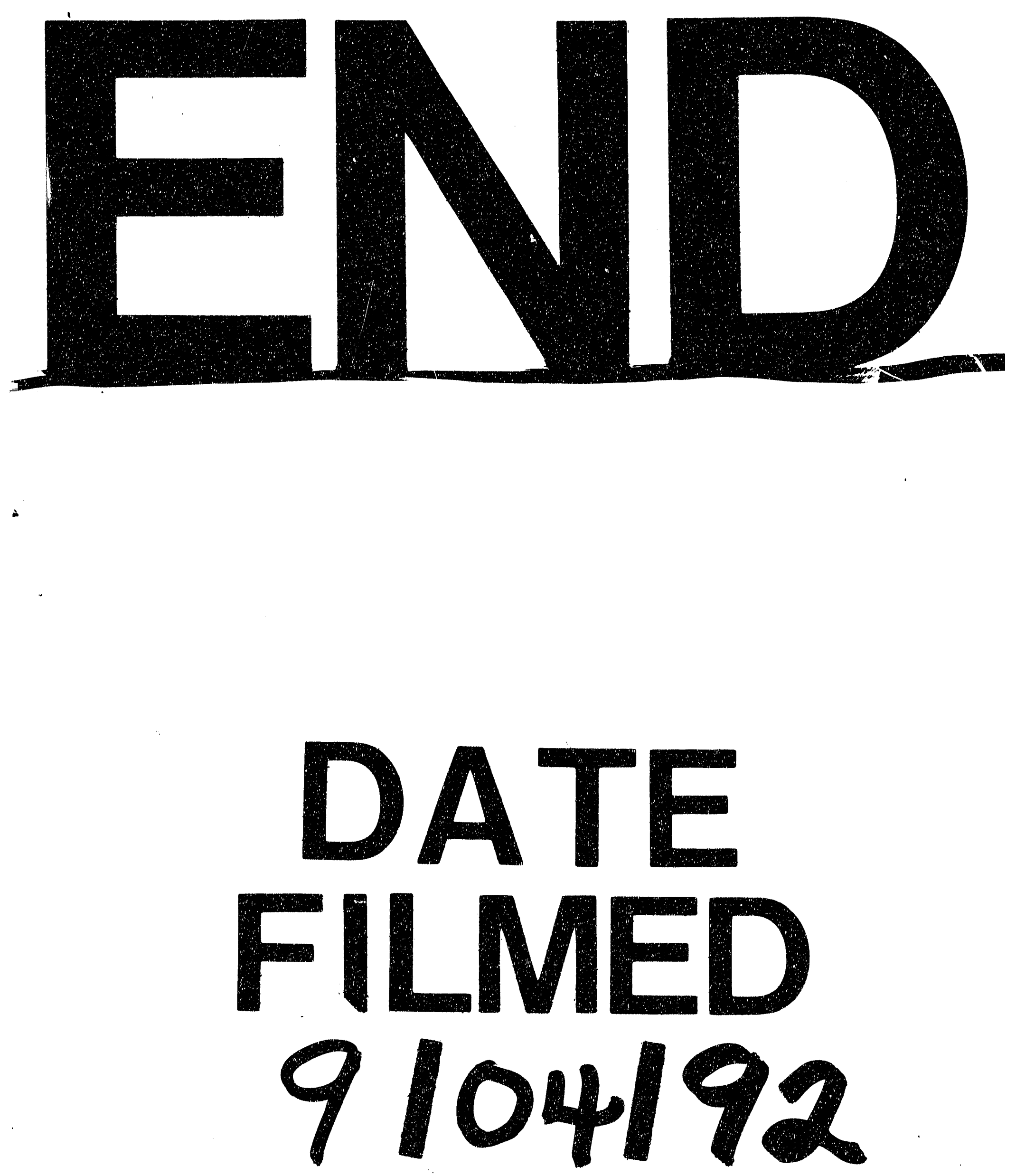
